\title{
Menstrual cup: awareness among reproductive women
}

\section{Shwetha Ballal K.*, Amritha Bhandary}

Department of Obstetrics and Gynecology, A. J. Institute of Medical Science, Mangalore, Karnataka, India

Received: 25 February 2020

Accepted: 02 March 2020

\section{*Correspondence:}

Dr. Shwetha Ballal K., E-mail: shwetha_ballal@rediff.com

Copyright: (C) the author(s), publisher and licensee Medip Academy. This is an open-access article distributed under the terms of the Creative Commons Attribution Non-Commercial License, which permits unrestricted non-commercial use, distribution, and reproduction in any medium, provided the original work is properly cited.

\begin{abstract}
Background: Menstrual cup is an alternative to sanitary pads, which has received attention in relatively small-scale studies in high income, and low- and middle-income countries, including among schoolgirls. Made of high-grade medical grade silicone (biodegradable) have the advantage of reuse, and can potentially last up to 10 years. Objective of this study was to assess and analyse the awareness regarding menstrual cup among the women of reproductive age group.

Methods: Data collected from the selected eligible participants by an interviewer administered study proforma. It is a descriptive cross-sectional study over 1 month in women in reproductive age in A. J. Institute Mangalore, Karnataka, India.

Results: A total $82 \%$ were aware about menstrual cup but only $2.6 \%$ have used it.

Conclusions: One challenge of menstruation that is taken for granted in affluent countries is the simple question of how to manage or contain the menstrual flow and what happens to a girl or woman who is not able to do this successfully. Menstrual hygiene management is therefore an increasingly important (yet often unrecognized) issue that is heavily intertwined with girls' education, empowerment, and social development.
\end{abstract}

Keywords: Awareness, Biodegradable, Menstrual cup, Menstrual hygiene, Reusable

\section{INTRODUCTION}

Menstruation is a normal biological process experienced by millions of women and girls around the world each month. Menarche signifies the start of a female's reproductive years and often marks her transition to full adult female status within a society. Age at menarche tends to be slightly later in resource-poor countries than in higher-income countries, yet an apparent decline in age at menarche has been documented in both developed and developing countries over the past few decades. ${ }^{1-4}$ One challenge of menstruation that is taken for granted in affluent countries is the simple question of how to manage or contain the menstrual flow and what happens to a girl or woman who is not able to do this successfully. The United Nations defines adequate menstrual hygiene management as "women and adolescent girls using a clean menstrual management material to absorb or collect blood that can be changed in privacy as often as necessary for the duration of the menstruation period, using soap and water for washing the body as required, and having access to facilities to dispose of used menstrual management materials." ${ }^{, 5}$ Particularly in poor countries, girls and women face substantial barriers to achieving adequate menstrual management. Gender equity in education has long been heralded as a cornerstone for social and economic development.

The education of girls and women holds a prominent position in both the United Nations' millennium development goals and in the recently adopted sustainable development Goals. ${ }^{6}$ Although much progress has been made since 2000, in many countries (especially in South Asia and sub-Saharan Africa) a large number of 
girls either never attend school or attend only a few years of primary school before dropping out. ${ }^{7}$ Furthermore, the number of out-of-school girls is rising again after years of improvement. $^{7}$

Earlier menarche and an increased emphasis on education has led to many adolescent girls are in school while menstruating. With a typical menstrual cycle lasting 25 to 30 days within which bleeding occurs for 4 to 6 days, post-menarcheal girls will experience menstrual bleeding on at least some school days every month. ${ }^{8}$ Menstrual hygiene management is therefore an increasingly important (yet often unrecognized) issue that is heavily intertwined with girls' education, empowerment, and social development.

An alternative to sanitary pads is the menstrual cup, which has received attention $\mathrm{n}$ in relatively small-scale studies in high income and low- and middle-income countries, including among schoolgirls. ${ }^{9-12}$ Made of highgrade medical grade silicone, rubber, latex or elastomer, these bell-shaped receptacles collect menstrual flow when inserted into the vaginal canal, and can be emptied and reinserted with a need to boil the cup only at the end of a cycle. ${ }^{13}$ Cups have the advantage of reuse, and can potentially last up to 10 years. First introduced in the 1930 's, there are now $\sim 100$ brands available worldwide marketed as an eco-friendly and cost-saving approach to menstrual care. ${ }^{13}$ Cups have been shown to be safe with no incumbent infection risk among European and North American women. ${ }^{10,14}$

Preliminary studies of acceptability in low and middle income countries suggest cups are a potential option for girls as well as women. ${ }^{11,12}$ Studies to date have reported outcomes based on women and girls' self-reported cup use, but have not physically evaluated actual cup use or their robustness for sustained use in impoverished settings where environmental hazards (extreme temperatures, household pests) may reduce shelf-life. ${ }^{15} \mathrm{~A}$ systematic review of MHM products recommended more rigorous ascertainment of cup use before large scale trials are conducted to determine cost-effectiveness. ${ }^{16}$

As part of a pilot study examining the feasibility and safety of menstrual cup use on outcomes such as school attrition, and sexual and reproductive infections among primary schoolgirls who have reached menarche in rural western Kenya, previous qualitative study demonstrated girls' reported cup use and acceptance. ${ }^{12,17}$ There have been few studies to assess the knowledge of MHM among the working adults.

In this view the study intended to study and assess the awareness and also knowledge, attitude and practices regarding menstrual cup among the women of reproductive age group and to analyse the factors associated with knowledge, attitude and practices regarding menstruation among the study population.

\section{METHODS}

This study was a descriptive cross-sectional study conducted in A. J. Institute of Medical Science Hospital, Mangalore and was studied for duration of one month. The data was collected from the selected eligible participants using an interviewer administered questionnaire.

The statistical parameters studied were: Awareness regarding menstrual cup and Knowledge, attitude and practice regarding menstrual cup among reproductive age. Age, education, occupation, SES and menstrual history etc., was considered as key explanatory variables.

The eligible study participants were selected from a teaching medical institution in the specified geographical locality. After obtaining the necessary administration approvals from the selected institutions, the selected women were approached and those willing to participate in the study were recruited. The relevant data was collected using an interviewer administered questionnaire.

The questionnaire contained data related demographic parameters, awareness, knowledge, attitude and practice. It was validated by consensus of 5 experts in the field. Pre-testing and further validation were done on 20 participants. Knowledge was assessed by assigning a score of " 0 " and " 1 " for each inappropriate and right answer, knowledge score $>/=$ median was considered to have good knowledge.

\section{Inclusion criteria}

- Women of reproductive age group (15 to 45 years age group) studying and working in the Institute.

\section{Exclusion criteria}

- Adolescent girls, who have not attained menarche

- Women with surgical menopause.

\section{Statistical analysis}

Descriptive analysis was carried out by mean and standard deviation for quantitative variables, frequency and proportion for categorical variables. Data was represented using appropriate diagrams. The association between explanatory variables and KAP was assessed by comparison foe man values for quantitative variables by unpaired t-test.

Categoric variables was compared by cross tabulation and comparison of percentages. Chi square test/Fisher's exact test was used to test statistical significance. $p$ value $<0.05$ will be considered statistically significant. IBM SPSS version 22 will be used for statistical analysis. 


\section{RESULTS}

A total 300 people were included in the final analysis.

Table 1: Descriptive analysis of demographic parameters in the study population $(\mathrm{N}=\mathbf{3 0 0})$.

\begin{tabular}{|c|c|c|}
\hline Parameter & Frequency & Percentage \\
\hline \multicolumn{3}{|l|}{ Age } \\
\hline $16-20$ years & 84 & $28.00 \%$ \\
\hline $21-25$ years & 114 & $38.00 \%$ \\
\hline $26-30$ years & 58 & $19.33 \%$ \\
\hline $31-35$ years & 17 & $5.67 \%$ \\
\hline $36-40$ years & 12 & $4.00 \%$ \\
\hline Above 40 years & 15 & $5.00 \%$ \\
\hline \multicolumn{3}{|l|}{ Educational status } \\
\hline Graduate & 62 & $20.67 \%$ \\
\hline Post graduate & 85 & $28.33 \%$ \\
\hline Under graduate & 152 & $50.67 \%$ \\
\hline Up to $2^{\text {nd }} P U$ & 1 & $0.33 \%$ \\
\hline \multicolumn{3}{|l|}{ Occupation } \\
\hline Doctor & 26 & $8.67 \%$ \\
\hline Not answered & 34 & $11.33 \%$ \\
\hline Paramedical staff & 6 & $2.00 \%$ \\
\hline Physiotherapist & 2 & $0.67 \%$ \\
\hline Receptionist/clerk & 19 & $6.33 \%$ \\
\hline Student-dental & 5 & $1.67 \%$ \\
\hline Student-medical & 144 & $48.00 \%$ \\
\hline Student-paramedical & 7 & $2.33 \%$ \\
\hline Student-physiotherapy & 57 & $19.00 \%$ \\
\hline \multicolumn{3}{|l|}{ Marital status } \\
\hline Married & 66 & $22.00 \%$ \\
\hline Unmarried & 234 & $78.00 \%$ \\
\hline \multicolumn{3}{|l|}{ Monthly income } \\
\hline Less than Rs.20,000 & 185 & $61.67 \%$ \\
\hline more than Rs.50,000 & 37 & $12.33 \%$ \\
\hline Rs. $20,000-50,000$ & 78 & $26.00 \%$ \\
\hline
\end{tabular}

In this study we had enrolled 300 candidates, among them $114(38 \%)$ were aged between 26 to 30 years, 12 (4\%) were aged between 36 to 40 years and $15(5 \%)$ were aged more than 40 years. It was also noted that 152 $(50.67 \%)$ were under graduates and $1(0.33 \%)$ has studied up to $2^{\text {nd }}$ PU. Regarding occupation $26(8.67 \%)$ were doctors, $144(48 \%)$ medical students. Among the study population, $66(22 \%)$ were married and $234(78 \%)$ were unmarried. $185(61.67 \%)$ had income less than Rs. 20,000 (Table 1).

Table 2: Awareness of menstrual cup among the study population.

\begin{tabular}{|lcc|}
\hline Parameter & \multicolumn{1}{|c|}{ Frequency } & \multicolumn{1}{l|}{ Percentages } \\
\hline Have you ever heard of menstrual cup? \\
\hline Yes & 246 & $82.00 \%$ \\
\hline No & 54 & $18.00 \%$ \\
\hline
\end{tabular}

Among the study population, 246 (82\%) knew about menstrual cup (Table 2).

Among the good knowledge, 87 (76.32\%) were aged between 21-25 years, $36(62.07 \%)$ were aged between 26-30 years, 9 (52.94\%) were aged between 31-35 years, $10(83.33 \%)$ were aged between $36-40$ years and 7 (46.67\%) were aged above 40 years.

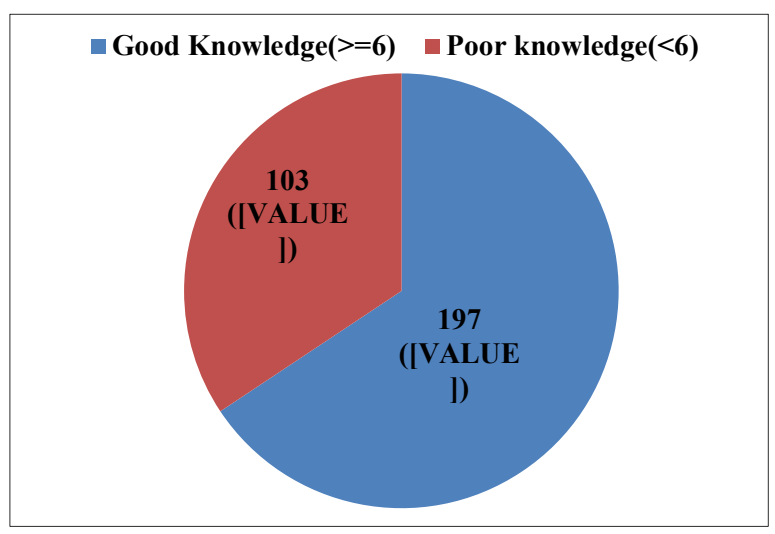

Figure 1: Knowledge regarding menstrual cup in the study population $(\mathrm{N}=300)$.

Among the poor knowledge, 27 (23.68\%) were aged between 21-25 years, $8(47.06 \%)$ were aged between 31 35 years, $2(16.67 \%)$ were aged between $36-40$ years and $8(53.33 \%)$ were aged above 40 years. The difference in the proportion of age group between knowledge category was statistically significant ( $\mathrm{p}$ value 0.029 ).

Among the good knowledge, 96 (66.67\%) were medical students.

Among the poor knowledge, 9 (34.62\%) were doctors, 14 $(73.68 \%)$ were receptionist/clerk, 48 (33.33\%) were medical students. The difference in the proportion of occupation between knowledge was statistically significant (p value 0.018) (Table 3) (Figure 1).

More than half of the study population knew that it is more beneficial than pad, but only $43.67 \%$ considered using it. Cumbersome to use, higher cost and poor availability were the common disadvantages reported. Less frequent change and less leakage were the most commonly reported advantages.

Of the study population only $2.67 \%$, actually used it. Out of 8 , only 3 had used it for 2-3 cycles, 5 had used it once. Most of them felt higher comfort level than pad. The cup was preferred for comfort, dryness and less odour. Insertion was easy for $37.5 \%$ participants and $87.5 \%$ participants found removal easy. There were few side effects like rashes and dryness. These results demonstrate that this reusable vaginal device has no significant health risks and is acceptable to many women. 
Table 3: Comparison of demographic parameters between knowledge category $(\mathrm{N}=600)$.

\begin{tabular}{|c|c|c|c|c|}
\hline \multirow[b]{2}{*}{ Parameter } & \multicolumn{2}{|c|}{ Knowledge category } & \multirow[b]{2}{*}{ Chi square } & \multirow[b]{2}{*}{ p value } \\
\hline & $\begin{array}{l}\text { Good knowledge } \\
(>=6)(\mathrm{N}=197)\end{array}$ & $\begin{array}{l}\text { Poor knowledge } \\
(<6)(N=103)\end{array}$ & & \\
\hline \multicolumn{5}{|l|}{ Age group } \\
\hline $16-20$ years $(\mathrm{N}=84)$ & $48(57.14 \%)$ & $36(42.86 \%)$ & \multirow{6}{*}{14.058} & \multirow{6}{*}{0.029} \\
\hline $21-25$ years $(\mathrm{N}=114)$ & $87(76.32 \%)$ & $27(23.68 \%)$ & & \\
\hline $26-30$ years $(\mathrm{N}=58)$ & $36(62.07 \%)$ & $22(37.93 \%)$ & & \\
\hline $31-35$ years $(\mathrm{N}=17)$ & $9(52.94 \%)$ & $8(47.06 \%)$ & & \\
\hline $36-40$ years $(\mathrm{N}=12)$ & $10(83.33 \%)$ & $2(16.67 \%)$ & & \\
\hline Above 40 years $(\mathrm{N}=15)$ & $7(46.67 \%)$ & $8(53.33 \%)$ & & \\
\hline \multicolumn{5}{|l|}{ Educational status } \\
\hline Graduate $(\mathrm{N}=62)$ & $47(75.81 \%)$ & $15(24.19 \%)$ & \multirow{3}{*}{3.579} & \multirow{3}{*}{0.167} \\
\hline Post graduate $(\mathrm{N}=85)$ & $54(63.53 \%)$ & $31(36.47 \%)$ & & \\
\hline Under graduate $(\mathrm{N}=153)$ & $96(62.75 \%)$ & $57(37.25 \%)$ & & \\
\hline \multicolumn{5}{|l|}{ Occupation } \\
\hline Student-paramedical $(\mathrm{N}=69)$ & $51(73.91 \%)$ & $18(26.09 \%)$ & \multirow{6}{*}{15.290} & \multirow{6}{*}{0.018} \\
\hline Paramedical staff $(\mathrm{N}=8)$ & $5(62.5 \%)$ & $3(37.5 \%)$ & & \\
\hline Doctor $(\mathrm{N}=26)$ & $17(65.38 \%)$ & $9(34.62 \%)$ & & \\
\hline Not answered $(\mathrm{N}=34)$ & $23(67.65 \%)$ & $11(32.35 \%)$ & & \\
\hline Receptionist/clerk $(\mathrm{N}=19)$ & $5(26.32 \%)$ & $14(73.68 \%)$ & & \\
\hline Student-medical $(\mathrm{N}=144)$ & $96(66.67 \%)$ & $48(33.33 \%)$ & & \\
\hline \multicolumn{5}{|l|}{ Marital Status } \\
\hline Married $(\mathrm{N}=66)$ & $36(54.55 \%)$ & $30(45.45 \%)$ & \multirow{2}{*}{4.642} & \multirow{2}{*}{0.031} \\
\hline Unmarried ( $\mathrm{N}=234)$ & $161(68.8 \%)$ & $73(31.2 \%)$ & & \\
\hline \multicolumn{5}{|l|}{ Monthly income } \\
\hline Less than Rs.20,000 $(\mathrm{N}=185)$ & $118(63.78 \%)$ & $67(36.22 \%)$ & \multirow{3}{*}{0.790} & \multirow{3}{*}{0.674} \\
\hline More than Rs.50,000 $(\mathrm{N}=37)$ & $25(67.57 \%)$ & $12(32.43 \%)$ & & \\
\hline Rs.20,000-50,000 (N = 78) & $54(69.23 \%)$ & $24(30.77 \%)$ & & \\
\hline
\end{tabular}

\section{DISCUSSION}

Majority of females belonged to 16-30 years of age with nearly half of them presenting with under-graduation level of education and most belonging to the medical fraternity. The proportion of unmarried study population was greater compared to married due to large participation of under-graduate's students. Majority of the study group showed monthly income less than 20 thousand. Various studies assessing the menstrual hygiene have shown to belonging to adolescent school aged group who have attained their menarche. ${ }^{18}$ However, in this study the study group comprised of medical under graduates and other paramedical staff.

Most of them used sanitary pad alone, or cloth, tampon and menstrual cup in combination to maintain sanitary hygiene during menstrual days. Indian studies have shown sanitary napkins to be used among majority of school going girls and adults as also witnessed in this study. ${ }^{19-21}$ This could be due to lack of popularity of menstrual cup over sanitary pads and cloth among these age groups or due to availability of napkins at primary health care centre at free of cost. ${ }^{21,22}$
Nearly $82 \%$ of the study population had good awareness of menstrual cup. An about $65.75 \%$ of the study group had good knowledge about menstrual cups. Around $43.67 \%$ of them were willing to accept menstrual cup as sanitary hygiene aid during menstrual days. In a metanalysis, $70 \%$ of adults together from 13 studies showed willingness to continue the use of menstrual cup. $^{22}$ Although, there was good awareness and knowledge about menstrual cup among present study group majority of them had not used it even once. And only $2.67 \%$ were found to have used Menstrual cup and a smaller number of them used only for only one cycle. Hence, further assessment of hygiene and leakage of menstrual cups use were beyond the scope of the study. Similar study in Gujarat showed the use of menstrual cup among adults 20 to 50 years of age to be more preferred it was easier to insert and remove, with good comfort, dryness and less odor and least side effects like rashes, dryness or infection. ${ }^{23}$

A study in Kenyan school girls aged 14-16 years were examined for safety of menstrual cups against sanitary napkins and pads found menstrual cups to be more effective as the established users showed less E-coli growth and no evidence of health issues. ${ }^{24}$ 
Although, from the studies it is learnt that menstrual cups were more convenient, portable and easy to store with extended wear time and greater freedom of movement. ${ }^{25}$ Advantages of menstrual cup as listed are easy and requires less water to clean and hence can be considered in situations of less water resources and avoids odour and discomfort due to internal placement which lacks in sanitary pads and cloth. ${ }^{25}$ Further, reuse of these cups is of economic advantage and reduces disposal of waste as compared to sanitary napkins. ${ }^{26}$ Due to these advantages many women prefer menstrual cup during their menstruating days. Quick adoption of cup use in $60 \%$ of them in 6 months was seen in Kakani CR et al, study and the acceptability among adolescent school girls in Nepal was also recorded. ${ }^{19,25}$ Higher acceptance rate was found in Kakani et al, compared to our study due to prior counselling of subjects. ${ }^{19}$ The acceptance to use cups in our study was low due to most study group were unmarried (virginity issues) and might be due to affordability to other aids of sanitary hygiene. Although the study group were aware of the practices and hygiene of cups the assessment of acceptance of the cup based on questionnaire should be further evaluated by prospective observational studies.

\section{CONCLUSION}

Despite the limitations of this study the knowledge, attitude and acceptance for the use of menstrual cups among the educated groups is well appreciated. Even though many people aware, the knowledge levels are poor and lot of misconceptions are over served in many. There is a huge gap between willingness to use and actual use. The use of menstrual cup among Indians especially in rural parts where the basic resources are denied can implement these cups as they are cost effective, reusable and require less water to clean and improve their hygiene as well. Menstrual hygiene management is therefore an increasingly important (yet often unrecognized) issue that is heavily intertwined with girls' education, empowerment, and social development. Hence, most importantly increasing the awareness of the use of cups and counselling programs emphasising on good habits of sanitary hygiene for females by government agencies through health workers should be considered as prime goal. Further in longer run these programmes can impact on larger population of women who are unaware of it. Targeted health education programmes are needed to enhance the KAP.

Funding: No funding sources

Conflict of interest: None declared

Ethical approval: The study was approved by the Institutional Ethics Committee

\section{REFERENCES}

1. Thomas F, Renaud F, Benefice E ea. International variability of ages at menarche and menopause: patterns and main determinants. Hum Biol. 2001;73:271-90.

2. McDowell MA, Brody DJ, JP H. Has age at menarche changed? Results from the National Health and Nutrition Examination Survey (NHANES) 19992004. J Adolesc Health. 2007;40:227-31.

3. Talma H, Schönbeck Y, van Dommelen P ea. Trends inmenarcheal age between 1955 and 2009 in the Netherlands. PLoS One. 2013;8:e60056.

4. Pathak PK, Tripathi N, SV S. Secular trends in menarcheal age in India-evidence from the Indian human development survey. PLoS One. 2014;9:e111027.

5. Sommer M. Overcoming the taboo: advancing the global agenda for menstrual hygiene management for schoolgirls. Am J Public Health. 2013;103:1556-9.

6. United Nations. Sustainable development knowledge platform (SDG Web site). Available at: https://sustainabledevelopment.un.org/sdgs.

Accessed 12 June 2019.

7. UNESCO Institute for Statistics. A growing number of children and adolescents are out of school as aid fails to meet the mark. 2015/ED/EFA/MRT/PP/22 REV. Available

at: http://unesdoc.unesco.org/images/0023/002336/2336 10e.pdf. Accessed 12 June 2019.

8. Reed BG, Carr BR. The normal menstrual cycle and the control of ovulation. In Endo text. 2018:1.

9. North BB, Oldham MJ. Preclinical, clinical, and over-the-counter post-marketing experience with a new vaginal cup: menstrual collection. J Women's Health. 2011;20(2):303-11.

10. Howard C, Rose CL, Trouton K, Stamm H, Marentette D, Kirkpatrick N, et al. FLOW (finding lasting options for women): multicentre randomized controlled trial comparing tampons with menstrual cups. Can Fam Physician. 2011;57:e208-15.

11. Averbach S, Sahin-Hodoglugil N, Musara P, Chipato T. Duet for menstrual protection: a feasibility study in Zimbabwe. Contracept. 2009;769:463-8.

12. Mason L, Laserson K, Oruko K, Nyothach E, Alexander K, Odhiambo $\mathrm{F}$, et al. Adolescent schoolgirls' experiences of menstrual cups and pads in rural western Kenya: a qualitative study. Waterlines. 2015;34:15-30.

13. Menstrual cup master list. 2016. Available at: https://menstrualcups. wordpress.com/menstrualcup-master-list/. Accessed 12 June 2019.

14. Stewart K, Greer R. Women's experience of using the Moon cup. J Obstet Gynaecol. 2010;30:285-7.

15. Phillips-Howard PA, Caruso B, Torondel B, Zulaika G, Sahin M, Sommer M. Menstrual hygiene management among adolescent schoolgirls in lowand middle-income countries: research priorities. Global Health Act. 2016;9(1):33032.

16. Sumpter C, Torondel B. A systematic review of the health and social effects of menstrual hygiene management. PloS One. 2013;8(4):e62004.

17. Juma J, Nyothach E, Laserson KF, Oduor C, Arita L, Ouma $\mathrm{C}$, et al. Examining the safety of menstrual 
cups among rural primary school girls in western Kenya: observational studies nested in a randomised controlled feasibility study. BMJ Open. 2017;7:e015429.

18. van Eijk AM, Laserson KF, Nyothach E, Oruko K, Omoto J, Mason L, et al. Use of menstrual cups among school girls: longitudinal observations nested in a randomised controlled feasibility study in rural western Kenya. Reprod Health. 2018;15(1):139.

19. Kakani CR, Bhatt JK. Study of adaptability and efficacy of menstrual cup in managing menstrual health and hygiene Int J Reprod Contracept Obstet Gynecol. 2017;6(7):3045-53.

20. Balamurugan SS, Shilpa S, Shaji S. A communitybased study on menstrual hygiene among reproductive age group women in a rural area, Tamil Nadu. J Basic Clin Repro Sci. 2014;3(2):83-7.

21. Mathiyalagen P, Peramasamy B, Vasudevan K, Basu M, Cherian J, Sundar B. A descriptive crosssectional study on menstrual hygiene and perceived reproductive morbidity among adolescent girls in a union territory. India. J Family Med Prima Care. 2017;6(2):360-5.

22. van Eijk AM, Zulaika G, Lenchner M, Mason L, Sivakami M, Nyothach E, et al. Menstrual cup use, leakage, acceptability, safety, and availability: a systematic review and meta-analysis. The Lancet Pub Health. 2019;4(8):e376-e93.

23. Kakani CR, Bhatt JK. Study of adaptability and efficacy of menstrual cup in managing menstrual health and hygiene. Int $\mathrm{J}$ Reprod Contracept Obstet Gynecol. 2017;6(7):3045-53.

24. Juma J, Nyothach E, Laserson KF, Oduor C, Arita L, Ouma $\mathrm{C}$, et al. Examining the safety of menstrual cups among rural primary school girls in western Kenya: observational studies nested in a randomised controlled feasibility study. BMJ Open. 2017;7(4):e015429.

25. Oster EFT, Thornton RE. Menstruation and education in Nepal. National Bureau of Economic Research Working Paper Series. 2009; 14853.

26. Bharadwaj S, Patkar A. Menstrual hygiene and management in developing countries: Taking stock. Mumbai. Junction Social. 2004;3:6.

Cite this article as: Ballal SK, Bhandary A. Menstrual cup: awareness among reproductive women. Int J Reprod Contracept Obstet Gynecol 2020;9:1382-7. 